\title{
O turismo rural pedagógico promovendo a multifuncionalidade da agricultura: análise de três experiências desenvolvidas no Brasil
}

\author{
Pedagogical rural tourism promoting the multifunctionality of agriculture: analysis of three experiences developed in \\ Brazil \\ El turismo rural pedagógico promoviendo la multifuncionalidad de la agricultura: análisis de tres experiencias \\ desarrolladas en Brasil
}

Angela Luciane Klein

Universidade Federal do Paraná (UFPR), Brasil

angelaklain@yahoo.com.br

DOI: https://doi.org/10.18472/cvt.19n2.2019.1477 Redalyc: http://www.redalyc.org/articulo.oa? id $=115460585007$

\author{
Ivo Elesbão \\ Universidade Federal de Santa Maria (UFSM), Brasil \\ ivoelesbao@yahoo.com.br
}

Marcelino de Souza

Universidade Federal do Rio Grande do Sul (UFRGS),

Brasil

marcelino.souza@uol.com.br

Recepção: 25 Agosto 2017

Aprovação: 15 Abril 2019

\section{Resumo:}

O objetivo da pesquisa foi analisar a função educativa desempenhada pela agricultura a partir do turismo rural pedagógico e suas relações com as funções social, ambiental, econômica, cultural e de saúde e segurança alimentar. Para tal, foram analisadas experiências nos estados de Santa Catarina e São Paulo e no Distrito Federal. Metodologicamente, utilizou-se abordagem qualitativa, a pesquisa bibliográfica e o uso de entrevistas semiestruturadas. Para a realização das entrevistas, definiu-se uma amostra intencional não probabilística onde foram entrevistados 22 empreendedores. Os resultados obtidos evidenciaram a multifuncionalidade na dimensão econômica ao possibilitar aos proprietários complementarem sua renda familiar; na dimensão social, com a melhoria da autoestima dos proprietários; na dimensão educativa ao possibilitar aos estudantes o contato com saberes e fazeres do meio rural; na dimensão ambiental por meio da educação ambiental, e, na dimensão de saúde e segurança alimentar, a partir do reconhecimento da origem dos alimentos. Conclui-se que a prática do turismo rural pedagógico pode se constituir em um instrumento importante para promoção da multifuncionalidade da agricultura.

Palavras-Chave: Turismo rural pedagógico, Desenvolvimento rural, Multifuncionalidade.

\section{Abstract:}

The objective of the research was to analyze the educational role played by agriculture from rural pedagogical tourism and its relations with social, environmental, economic, cultural and health and food safety functions. For this, experiences were analyzed in the States of Santa Catarina, São Paulo and Federal District. Methodologically, a qualitative approach was used, bibliographical research and the use of semi-structured interviews. For the interviews, a non-probabilistic intentional sample was defined where 22 entrepreneurs were interviewed. The results obtained evidenced the multifunctionality in the economic dimension by allowing the owners to complement their family income; In the social dimension, with the improvement of the selfesteem of the owners; In the educational dimension by enabling students to get acquainted with rural knowledge and activities; In the environmental dimension through environmental education, and in the health and food safety dimension, from the recognition of the origin of food. It is concluded that the practice of rural tourism education can be an important instrument to promote the multifunctionality of agriculture.

KEYWORDS: Pedagogical rural tourism, Rural development, Multifunctionality.

\section{Resumen:}

El objetivo de la investigación fue analizar la función educativa desempeñada por la agricultura a partir del turismo rural pedagógico y sus relaciones con las funciones social, ambiental, económica, cultural y de salud y seguridad alimentaria. Para ello, se 
analizaron experiencias en los estados de Santa Catarina y São Paulo y el Distrito Federal. Metodológicamente, se utilizó abordaje cualitativo, la investigación bibliográfica y el uso de entrevistas semiestructuradas. Para la realización de las entrevistas se definió una muestra intencional no probabilística donde fueron entrevistados 22 emprendedores. Los resultados obtenidos evidenciaron la multifuncionalidad en la dimensión económica al posibilitar a los propietarios complementar su ingreso familiar; En la dimensión social, con la mejora de la autoestima de los propietarios; En la dimensión educativa al posibilitar a los estudiantes el contacto con saberes y hacer del medio rural; En la dimensión ambiental a través de la educación ambiental, y en la dimensión de salud y seguridad alimentaria, a partir del reconocimiento del origen de los alimentos. Se concluye que la práctica del turismo rural pedagógico puede constituirse en un instrumento importante para la promoción de la multifuncionalidad de la agricultura.

Palabras Clave: Turismo rural pedagógico, Desarrollo rural, Multifuncionalidad.

\section{INTRODUÇÃO}

Diante do processo de revalorização do mundo rural, a agricultura também passa a adquirir uma nova dimensão, decorrente das suas novas funções, as quais vão muito além da produção primária de alimentos e matérias-primas. Ela se torna responsável também pela disponibilidade e qualidade dos alimentos, pela conservação dos recursos naturais e preservação do patrimônio cultural, bem como pela reprodução socioeconômica das famílias rurais (WANDERLEY, 2003).

Esse caráter multifuncional da agricultura possibilita uma reestruturação na maneira de conceber o desenvolvimento rural, que passa de uma visão setorial para uma visão integrada e em conexão com outros setores da sociedade.

Formulado originalmente no contexto europeu, o conceito de multifuncionalidade da agricultura refere-se a "[...] todos os produtos, equipamentos e serviços criados por atividades agrícolas em benefício da economia e da sociedade em geral" (LOSCH, 2004, p. 340). Tal característica permite que se coloquem em cena várias potencialidades do meio rural e da atividade agrícola que até recentemente não eram valorizadas pela sociedade.

Dentro dessa perspectiva, Marsden e Sonnino (2008) destacam três condições básicas de uma agricultura multifuncional visando contribuir para o desenvolvimento rural: aumento da renda e oportunidades de emprego para o setor agrícola; contribuição para a construção de uma nova política do setor agrícola que corresponda às necessidades e expectativas da sociedade; e redefinição e reconfiguração dos espaços rurais dentro e fora da propriedade.

Carneiro e Maluf (2003) destacam ainda que o enfoque da multifuncionalidade possibilita não apenas a compreensão acerca da inserção de diferentes tipos de famílias rurais nesse universo, mas, também, a legitimação de formas de produção e de fontes de renda que, na maioria das vezes, permanece alheia aos quadros analíticos de caráter hegemônico.

Apesar de apresentarem suas especificidades, essas funções permitem uma nova representação social sobre o rural, apoiada na valorização positiva da natureza e do patrimônio cultural dos espaços "rurais" (CARNEIRO; MALUF, 2003). Nesse cenário, destaca-se o turismo rural, uma atividade que dentro do contexto da multifuncionalidade, pode representar uma importante estratégia de desenvolvimento local, favorecendo a ativação das áreas rurais, a conservação da natureza e a criação e/ou manutenção de postos de trabalho.

Sznajder, Przezbórska e Scrimgeour (2009) destacam um conjunto de características e funções do turismo rural que evidenciam exatamente esse caráter multifuncional. Conforme esses autores, o turismo rural apresenta três características básicas: a primeira delas referindo-se à possibilidade de satisfazer necessidades humanas, por meio da participação prática no processo de produção de alimentos, na vida de uma família e na comunidade rural; a segunda, relacionada à possibilidade de satisfazer a necessidade cognitiva humana ou etnográfica dentro da produção agrícola; e a terceira característica compreende a possibilidade de satisfazer necessidades emocionais, a partir do contato direto com animais domésticos, plantas, produtos de 
processamento, e por meio de diferentes experiências vivenciadas no rural idílico associado a uma atmosfera de rusticidade e sossego.

Esse conjunto de características e funções do turismo rural converge para os aspectos visualizados na recente modalidade do turismo denominada de turismo rural pedagógico, cujo objetivo principal é facilitar o processo de ensino e aprendizagem por meio da articulação entre teoria e prática.

Sob essa perspectiva, as propriedades rurais passam a receber um novo enfoque, tornando-se ambientes pedagógicos valorosos que possibilitam a realização de uma ampla gama de atividades educativas, utilizando como recurso didático a produção agropecuária, a agricultura e os recursos naturais e culturais ali existentes.

A compreensão da importância atribuída às propriedades rurais, enquanto ferramentas de ensino, tem se difundido de modo significativo em países como Estados Unidos, Japão e, sobretudo, da Europa Ocidental, onde diferentes projetos de cooperação entre escolas e propriedades rurais vêm sendo desenvolvidos há mais de uma década (KLEIN, 2012).

Conforme Caffarelli et al. (2010), no ano de 2001, uma comissão interministerial da França, composta pelos Ministérios da Educação Nacional, da Agricultura e Pesca, do Desenvolvimento Territorial e Ambiental, da Juventude e dos Esportes e, recentemente, pelo Ministério da Justiça, publicou uma circular que definiu as estruturas e o papel das propriedades rurais que desenvolvem atividades pedagógicas, bem como os objetivos e os tipos de públicos.

De acordo com esse documento, a propriedade rural pedagógica ${ }^{[1]}$ caracteriza-se como uma estrutura com criação de animais e/ou culturas, que recebe crianças e jovens da escola e fora dela, podendo ser subdividida em dois tipos: as propriedades de animação e as explorações agrícolas. A primeira delas compreende as propriedades urbanas ou periurbanas que apresentam pouca ou nenhuma produção agrícola, mas que dispõem de uma diversidade de espécies de animais domésticos; estas foram criadas prioritariamente para atender as crianças, porém, seu público tem se tornado cada vez mais variado. Já as explorações agrícolas compreendem as propriedades rurais que, além de manter a sua função primária de produção, também desenvolvem atividades educativas, recebendo grupos de crianças e jovens de maneira regular. Elas possibilitam aos produtores rurais diversificarem suas atividades, ao mesmo tempo que permitem às crianças e jovens a descoberta de um outro mundo, o mundo rural (CAFFARELLI et al., 2010) ${ }^{[2]}$.

Segundo Nasolini (2005), as propriedades rurais pedagógicas, por permitirem a descoberta desse universo, a partir de uma abordagem ativa junto aos animais e às plantas, favorecem maior atenção ao meio ambiente e à valorização da origem das coisas, tornando, por conseguinte, uma excelente oportunidade de ampliação e reconhecimento do papel do agricultor para o desenvolvimento sustentável.

Bertacci (2005) ressalta ainda que as propriedades rurais pedagógicas podem representar um verdadeiro laboratório ao ar livre, contemplado por um universo repleto de possibilidades e valores educacionais que são oferecidos às escolas, como banco de dados a ser utilizado na plataforma curricular. Nesse contexto, o ambiente se torna um lugar de exploração e observação direta, favorecendo a experiência pessoal e experimental, estimulando o desenvolvimento de diferentes habilidades.

De acordo com Jolly et al. (2004, p. 633), a utilização da propriedade rural como recurso pedagógico constitui-se em importante "fonte de renda para o agricultor, bem como uma plataforma pedagógica para o ensino e como fonte de identidade para uma população que está cada vez mais distante da agricultura e produção primária”. Além disso, em virtude de suas características, esses ambientes representam um elemento de fundamental importância para a promoção da saúde e nutrição infantil, uma vez que possibilitam o desenvolvimento de hábitos alimentares saudáveis, contribuindo também para a formação pessoal e construção da identidade dos alunos.

Nesse sentido, conforme destaca Gurrieri (2008), as propriedades rurais pedagógicas no contexto atual, permitem, entre outros aspectos, uma conexão direta entre a cidade e o campo, entre o produtor e o cidadão, entre o agricultor e o consumidor, constituindo-se uma importante ferramenta, capaz de impedir a dispersão 
do patrimônio sociocultural existente no meio rural, relacionado à produção de alimentos, à terra, à natureza e ao meio ambiente.

O resultado dessa conexão emerge no reconhecimento das propriedades rurais e, mais especificamente, na prática do turismo rural pedagógico, enquanto uma estratégia socioeconômica em potencial, que pode favorecer tanto os agricultores rurais, na medida em que gera rendas complementares e a difusão de seus conhecimentos e saberes práticos, quanto os estudantes, a partir do momento em que possibilita um aprendizado diferenciado e significativo, permitindo o contato direto com elementos da natureza e a realização de atividades práticas em um contexto que vai muito além da sala de aula, favorecendo a educação ambiental e nutricional.

Uma série de experiências internacionais envolvendo projetos de cooperação entre propriedades rurais e escolas de educação básica têm evidenciado a importância desse tipo de atividade, não apenas em termos educacionais e econômicos, mas, também, sociais, ambientais e culturais. Em países como a França, por exemplo, as inúmeras propriedades rurais pedagógicas existentes no meio rural têm se revelado como uma atividade de caráter exemplar no quadro de um desenvolvimento sustentável. Conforme Caffarelli et al. (2010), isso se deve ao fato de que essas atividades contemplam um conjunto significativo de objetivos que vão desde aspectos econômicos (possibilidade de rendas complementares), ecológicos (educação ambiental), patrimoniais (preservação do patrimônio histórico e paisagístico), até sociais (intercâmbio entre o urbano e o rural), favorecendo desse modo o reconhecimento do papel do agricultor e, sobretudo, da agricultura no processo de aprendizagem e valorização do meio ambiente.

A compreensão do relevante papel desempenhado pelas propriedades rurais no âmbito da educação também está presente na Noruega. Os resultados obtidos com tal experiência têm sido bastante promissores, tornando-se uma referência para outros países que almejam realizar trabalho semelhante (KROGH et al., 2004).

Segundo Napoli (2006), na Itália, no ano de 2000 foram averiguadas 273 propriedades rurais pedagógicas, destacando-se a região de Emilia-Romagna, que à época já contava com 115 propriedades rurais envolvidas com atividades de caráter pedagógico. Os objetivos dos projetos visam, sobretudo, reforçar a identidade local e promover a valorização dos produtos alimentícios típicos e as explorações agrícolas, o que, por sua vez, favorece uma maior conscientização da função social desempenhada pela agricultura e também pelos espaços rurais.

Nos EUA, especificamente no estado da Pensilvânia, o pilar de sustentação das atividades promovidas nas propriedades rurais em parceria com as escolas está na preocupação com aspectos relacionados à obesidade infantil e diabetes e a promoção de um estilo de vida mais saudável e sustentável (HINRICHS et al., 2008).

Já no Japão, um programa pedagógico envolvendo um grupo de agricultores donos de propriedades leiteiras que oferecem serviços de caráter educativo aos visitantes, em especial às crianças e jovens das escolas locais, vem sendo desenvolvido desde 2000, produzindo efeitos positivos em termos de aprendizagem tanto aos visitantes como também aos próprios agricultores, ao passo que estes têm a oportunidade de descobrir novas possibilidades para a agricultura (OHE, 2009).

No cenário brasileiro já estão sendo desenvolvidas algumas experiências envolvendo a prática de atividades pedagógicas no âmbito das propriedades rurais. Partindo de tais considerações, teve-se como principal objetivo analisar a função educativa desempenhada pela agricultura a partir da prática do turismo rural pedagógico e a sua relação com as funções social, ambiental, econômica, cultural e de saúde e segurança alimentar, tendo como base empírica três experiências que estão sendo desenvolvidas nos estados de Santa Catarina e São Paulo e no Distrito Federal. O estudo foi feito a partir de um recorte do projeto de pesquisa intitulado "O turismo rural pedagógico sob o viés da multifuncionalidade da agricultura: análise a partir de três experiências desenvolvidas nos estados de Santa Catarina e São Paulo e no Distrito Federal”. [3]

As especificidades de cada experiência apresentam-se, sobretudo, nos objetivos propostos e nos contextos sociais e culturais nos quais estão inseridas. Contudo, essas experiências compartilham de uma mesma 
finalidade, qual seja, a de desenvolver atividades pedagógicas no âmbito da propriedade rural, voltadas principalmente para grupos escolares, utilizando como recurso didático a agricultura e a produção agropecuária, com o intuito de facilitar o processo de aprendizagem e o conhecimento da realidade rural.

\section{PROCEDIMENTOS METODOLÓGICOS}

$\mathrm{O}$ presente artigo compreende um recorte do projeto de pesquisa científica intitulada " $\mathrm{O}$ turismo rural pedagógico sob o viés da multifuncionalidade da agricultura: análise a partir de três experiências desenvolvidas nos estados de Santa Catarina e São Paulo e no Distrito Federal”, e que teve como principal objetivo analisar a função educativa desempenhada pela agricultura a partir da prática do turismo rural pedagógico e a sua relação com as funções social, ambiental, econômica, cultural e de saúde e segurança alimentar.

Os procedimentos metodológicos utilizados no referido estudo compreenderam a pesquisa bibliográfica acerca da literatura existente e entrevistas semiestruturadas, realizadas com os proprietários, donos das propriedades rurais que fazem parte das três experiências pesquisadas.

A primeira dessas experiências contemplou o estudo do projeto de turismo pedagógico "Viva Ciranda", no município de Joinville, no estado de Santa Catarina. O projeto compreende um conjunto de propriedades rurais que desenvolvem atividades pedagógicas voltadas especificamente para crianças do ensino fundamental, em um processo de cooperação com a Secretaria de Educação do município.

Nesse projeto, a coleta dos dados foi realizada no mês de março de 2013 e contemplou oito proprietários rurais que desenvolvem atividades educativas voltadas para escolares: Propriedade do Senhor Ango Kersten; Propriedade da Família Schroeder; Propriedade Agrícola da Ilha; Sítio Vale das Nascentes; Apiário PFAU; Propriedade da Família Jacobi; Propriedade Rancho Alegre; e Propriedade Recanto das Arrozeiras.

A segunda experiência estudada refere-se ao Projeto "Turismo Rural e Escola - Fazendo Eco", desenvolvido na cidade de Brasília, Distrito Federal. A iniciativa foi uma proposta do Sindicato de Turismo Rural e Ecológico do Distrito Federal em parceria com o Sindicato das Escolas Particulares (Sinepe) e com o Serviço Brasileiro de Apoio às Micro e Pequenas Empresas (Sebrae), tendo como objetivo principal promover a ampliação dos espaços escolares a partir de atividades de caráter pedagógico desenvolvidas em nove propriedades participantes. Foram visitados para a coleta de dados da pesquisa cinco empreendimentos, sendo eles os seguintes: Centro de Turismo Rural Pedagógico Ver de Perto, Fazenda Recreio Dinizlândia, Fazenda Velha, Rancho Canabrava e Solar da Águia. As entrevistas foram realizadas entre os dias 26 de fevereiro e 1 de março de 2013.

A terceira experiência que foi objeto da pesquisa diz respeito ao Roteiro do Turismo Rural Pedagógico do Estado de São Paulo. O referido roteiro contempla um conjunto de 16 propriedades rurais presentes em dez municípios localizados no estado de São Paulo e um fora do estado, em Minas Gerais e que compreende o Roteiro do Turismo Rural Pedagógico do Estado de São Paulo. As propriedades pesquisadas foram as seguintes: Chácara do Rosário, Fazenda Santo Antônio da Bela Vista e Camping Casarão, situadas no município de Itu; Fazenda Nova e Fazenda Santo Antônio da Água Limpa, ambas localizadas no município de Mococa; Fazenda Ituaú, localizada no município de Salto; Sítio Sakaguti, localizado no município de Piedade; Fazenda dos Coqueiros e Fazenda Loanda, ambas situadas no município de Bananal. Nesses empreendimentos, a coleta de dados ocorreu no período de janeiro a agosto de 2013.

Ressaltamos que os depoimentos dos empreendedores foram transcritos, e utilizados na análise dos dados, mas sem identificação, sendo utilizado para isso um código formado por letras e números a fim de manter sob sigilo a identidade dos entrevistados na pesquisa. Para isso, foram utilizadas as letras "SC" para os entrevistados de Santa Catarina, as letras "DF” para os entrevistados do Distrito Federal e as letras "SP” para os entrevistados de São Paulo, e os números apresentados na sequência serviram para indicar a ordem da realização das respectivas entrevistas. 


\section{A MULTIFUNCIONALIDADE DO TURISMO RURAL PEDAGÓGICO}

Em relação às motivações de ingresso e permanência na atividade de turismo rural pedagógico no Projeto Viva Ciranda, localizado no estado de Santa Catarina, o fato mais citado refere-se ao retorno financeiro, ao aumento da renda familiar. O segundo aspecto mais citado está relacionado à qualidade de vida proporcionada e o retorno pessoal. Constatou-se, ainda, que o interesse em permanecer na atividade evidencia-se, sobretudo, a partir do momento em que há valorização por parte da comunidade e dos grupos de visitantes acerca da propriedade, das atividades propostas e do trabalho desenvolvido. Esse reconhecimento estimula a autoestima dos proprietários que passam a ter mais gosto em apresentar sua propriedade e expor seus saberes e fazeres aos grupos recebidos.

No Distrito Federal, entre as principais motivações para o ingresso na atividade de turismo rural pedagógico estão questões relacionadas à atividade profissional anteriormente desenvolvida, à possibilidade de conhecer uma experiência modelo e ao patrimônio histórico da propriedade, permeadas também pela satisfação do trabalho com escolares.

As motivações para a permanência na atividade são praticamente as mesmas manifestadas para o ingresso e que vão da satisfação do trabalho com escolares à possibilidade de ocupação produtiva das estruturas que ficam praticamente ociosas durante os dias da semana.

Nos empreendimentos pesquisados em São Paulo, as principais motivações para o ingresso e a permanência na atividade de turismo rural pedagógico não diferem muito e estão relacionadas à busca de outra fonte de renda com base nos recursos existentes, mas também o gosto por receber pessoas e contar sobre a história do local, permitir que as crianças conheçam como é um dia no campo, e o gosto pela atividade que exerce, conforme encontra-se expresso no depoimento do entrevistado apresentado a seguir:

Agregar valor à propriedade e reciclar a propriedade numa atividade importante, pedagógica. Aqui é um recurso pedagógico, para mim parece óbvio que é um lugar natural e importante para trazer os estudantes para aprender alguma coisa. (SP4).

Em um dos empreendimentos, o ingresso na atividade de turismo rural pedagógico foi motivado pela observação de que havia demanda e mercado para desenvolver esse tipo de atividade, pois "as escolas buscavam algo diferente além do lazer e, dessa forma, pode-se aproveitar melhor a área da propriedade” (SP3).

Outra questão abordada na entrevista refere-se à média mensal de visitantes em cada propriedade e o perfil do público recebido. Conforme constatado, em Santa Catarina a média de visitantes diferencia-se muito de uma propriedade para outra. Aquelas que estão atuando há mais tempo com o turismo rural pedagógico chegam a atender 7 a 8 mil crianças por ano. Já as propriedades que se inseriram recentemente, o número de visitantes no ano de 2012 girou em torno de 3 mil. Em outras propriedades a média mensal é de 50 visitantes, havendo um aumento significativo desse número nos meses de outubro a dezembro.

No Distrito Federal não foi possível identificar o número médio mensal de visitantes, pois, conforme o depoimento do entrevistado: "não tenho um quantitativo certo, pois depende de muita coisa" (DF1), ou seja, "eu não tive praticamente uma média mensal, sabe, porque recebi esporadicamente, esporadicamente, recebi muito assim, porque a professora me conhece, aí telefona” (DF2).

Nos empreendimentos em São Paulo foi difícil quantificar uma média mensal de visitantes, pois há uma propriedade que recebe em média 30 alunos por mês, outra que em média recebe de 50 a 100 alunos por mês, passando por uma que recebeu no ano de 2012 cerca de 4.000 alunos e outra que nesse mesmo ano recebeu cerca de 7.000 alunos.

O valor cobrado em Santa Catarina é o mesmo em todas as propriedades e custa $\mathrm{R} \$$ 5,00 por pessoa. Há locais em que o valor sofre alterações se o visitante optar por realizar café da manhã ou almoço, além das atividades propostas no roteiro pedagógico. Além do ingresso cobrado por pessoa, muitas propriedades também disponibilizam produtos (cultivados e/ou processados na propriedade) para comercialização, garantindo lucros extras com a atividade. 
No Distrito Federal existe cobrança de uma taxa de visitação nos empreendimentos de turismo rural pedagógico que pode variar de $\mathrm{R} \$ 40,00$ a $\mathrm{R} \$ 60,00$ para atividades durante todo o dia. Esse valor pode ser menor se for por meio período, sendo que em um dos empreendimentos "é nessa base de 30 reais por um período simples" (DF1). Observou-se que alguns empreendimentos fazem diferenciação de preços para escolas públicas e particulares.

Nos empreendimentos em São Paulo também existe cobrança de taxa de visitação nos empreendimentos de turismo rural pedagógico sendo bastante variável. As taxas podem variar de $\mathrm{R} \$ 10,00$ por aluno de instituição particular e $\mathrm{R} \$ 5,00$ por aluno de instituição pública até $\mathrm{R} \$ 60,00$ por período integral. No geral, o turno integral, incluindo alimentação, gira em torno de $\mathrm{R} \$ 50,00$ em algumas propriedades.

Em Santa Catarina, os benefícios decorrentes da prática do turismo rural pedagógico, portanto, perpassam por diferentes esferas, a começar pela econômica e social. Conforme constatado, praticamente todos os proprietários consideram a atividade não apenas rentável, mas um elemento importante que favorece a autoestima, possibilita trocas de experiências, melhoria da qualidade de vida da família e possibilidade de os mais jovens permanecerem no meio rural.

Nesse sentido, conforme depoimento de um dos entrevistados, a finalidade não estaria nos ganhos financeiros provenientes da recepção dos grupos, mas sim nas contribuições que essas atividades podem trazer em termos sociais e ambientais:

A gente não está visando a questão econômica, mas sim pensando na questão social e fazer com que a gente consiga ajudar a mudar gerações, no sentido de fazer com que essas crianças nesse período de aprendizado possam saber que esse setor existe, que a questão de valorizar o plantio de uma árvore é superimportante, tanto no meio rural quanto no meio urbano (SC3).

A prática do turismo rural pedagógico no Distrito Federal possibilitou uma série de benefícios segundo os entrevistados. Entre eles merece destaque a satisfação pessoal proporcionada pelo trabalho com os escolares durante as visitas às propriedades rurais.

Também foi comentada a contribuição para a geração de empregos, "porque aqui nós começamos a estimular outras pessoas a trabalharem, aqui da comunidade mesmo, pessoas sem muita perspectiva de emprego, nós aproveitamos, com treinamento, e trouxemos esse povo para perto da gente" (DF1). Além disso, "o MEC considerou uma nova tecnologia social. Uma coisa muito importante do ponto de vista da educação. Então para a comunidade foi muito bom. Para as escolas foi excelente” (DF2). Vale também destacar a complementaridade do trabalho pedagógico com os outros serviços turísticos oferecidos.

Em São Paulo, além do retorno financeiro apontado pela maioria dos entrevistados, há menção a outros aspectos importantes, com destaque para a satisfação pessoal, passando pelo convívio com outras pessoas, a possibilidade de passar adiante o conhecimento de vida no campo, o prazer de receber as crianças e perceber a melhora no comportamento destas. Como destaca um dos entrevistados em relação aos benefícios: "nós sempre aprendemos com sugestões, receitas, alguns visitantes depois voltam para se hospedar na propriedade" (SP5).

A análise das funções socioeducativas do turismo rural pedagógico permitiu evidenciar que em Santa Catarina praticamente todas as atividades educativas propostas utilizam as atividades produtivas e/ou os recursos naturais e culturais existentes nas propriedades. O contato com os animais constitui um dos aspectos mais destacados pelos proprietários. Trata-se de uma atividade que desperta o interesse das crianças, tornando-se uma das principais atrações do roteiro. Nas propriedades onde não há esse tipo de experiência, o destaque está nas atividades mais práticas, que envolvem movimento e ludicidade, a exemplo do passeio de trator. $\mathrm{O}$ roteiro de atividades proposto, embora tenha um foco, inclui atividades que contemplam vários temas.

Outro elemento importante ressaltado nas entrevistas refere-se às questões ambientais. Há um interesse declarado por parte dos proprietários em contribuir para a conscientização das crianças sobre a importância de preservar o meio ambiente, conforme depoimento de um dos entrevistados: 
Mostrar às crianças a importância das plantas para a vida delas, para o meio ambiente, mostrar a importância de uma árvore... Ensinar elas a cuidar das flores, mostrar o jardim e aí mostrar que isso não acontece sozinho, que precisa de cuidado (SC3).

No Distrito Federal são desenvolvidas algumas atividades educativas que possuem relação com as questões ligadas à preservação do meio ambiente, pois "nós temos várias, porque o nosso trabalho todo é baseado na preservação do meio ambiente" (DF3) e "isso aí a gente passa muito pra criança, gente isso aqui é a nossa casa, nosso ambiente, nós temos que preservar, isso aí é batido desde que a criança chega até a hora que ela sai. É a ideia de mostrar a importância da preservação da natureza pra criança" (DF5).

Entre os principais aspectos relacionados à educação ambiental que podem ser aprendidos a partir das atividades educativas desenvolvidas nas propriedades estão a preservação do meio ambiente, evidenciada no cuidado com água e a vegetação, além do lixo e sua destinação: "Ali nós temos o laboratório com minhocário, com a parte seletiva de lixo. Ensina a criança a separar o sólido do líquido, do alimento, do metal, do vidro" (DF1); “Aqui a gente fala muito sobre a preservação, a reutilização e os cuidados com a água, isso aqui é muito debatido" (DF3); "A gente trabalha muito essa parte da vegetação, do clima, a educação ambiental, como que você procede na propriedade rural" (DF4).

As atividades educativas voltadas para o público escolar tinham objetivos variados, que passavam pelo ensino disciplinar, a educação ambiental, patrimonial e histórica, além de outras práticas que são transversais aos conteúdos disciplinares.

Na maioria dos empreendimentos pesquisados em São Paulo são abordadas, mesmo que tangencialmente, questões de educação ambiental. Assim trabalham-se a "preservação da água, da natureza e o desenvolvimento sustentável (uso dos recursos naturais sem agressão ao meio ambiente)" (SP3). Podem ser aprendidas características dos diferentes biomas, preservação das matas, conscientização do uso da água, a questão do lixo, reciclagem, entre outras.

O quadro de questões relacionadas à função de segurança alimentar e saúde do turismo rural pedagógico teve como propósito averiguar a forma como as questões de educação alimentar e nutricional são trabalhadas nas atividades propostas. Apesar da constatação de que tal tema está diretamente ligado a várias atividades desenvolvidas na maioria das propriedades, verificou-se que esse bloco não conseguiu atingir o objetivo proposto, uma vez que não houve muito retorno por parte dos proprietários em relação às questões apresentadas.

Em relação às atividades educativas propostas que evidenciam uma preocupação com a produção de alimentos e alimentação saudável, citaram-se como exemplos nas propriedades de Santa Catarina a produção de melado e a origem dos alimentos, o processo de produção agroecológico e consumo de alimentos orgânicos, produção do mel e tipos de plantações de arroz. A partir de algumas situações, muitas crianças "descobrem" a origem de alguns alimentos, a exemplo do leite e dos ovos, além de conhecerem o processo de produção orgânica.

Muitos vêm aqui e acham que o leite sai da geladeira ou da caixinha, então essa experiência de poder ordenhar uma cabra, que são animais dóceis, mostrando de onde vem o leite, o ovo e também mostrar para elas a parte da produção orgânica, que tem como trabalhar sem agrotóxico e com qualidade, tudo isso é muito importante (SC2).

Quando questionados se há consumo de alimentos produzidos na propriedade durante essas atividades, apenas três proprietários declararam que sim: uma propriedade com a degustação de sachês de melado; outra com o consumo de sachês de mel; e outra propriedade onde é servido lanche com produtos coloniais (doces, cucas e pães) produzidos com alimentos da propriedade.

Em três dos cinco empreendimentos pesquisados no Distrito Federal existem atividades educativas desenvolvidas relacionadas à alimentação saudável, à forma de produção e origem dos alimentos como o “aproveitamento das frutas, dos legumes. [...]. A gente dá aula sobre reaproveitamento de resto de alimentos. Pega uma abóbora, tira a casca, e fazemos uma série de cozidos com a casca da abóbora, e casca de fruta também; dificilmente joga alguma coisa fora" (DF1). 
Um dos empreendimentos que possuem esse tipo de atividade pedagógica afirmou que o objetivo de realização das atividades durante a visita "é um aproveitamento da disponibilidade da criança, para aí eles aprenderem, ocupar o tempo e saber criar. O segundo, vem a parte financeira, eles aprenderem a utilizar resto de comida que normalmente jogam fora, e que pode ser transformado" (DF1) e que "elas têm muito interesse" (DF1).

A maioria dos empreendimentos utiliza algum produto produzido na propriedade no preparo dos alimentos que são consumidos no momento da visita, entre eles "todos os temperos" (DF3) e o "leite, era muito de manhã o leite. [...]. E frutas quando tem. É leite, queijo, requeijão, bolo de milho, pão de queijo. A mandioca também é daqui. Banana" (DF2).

O benefício que as atividades educativas, envolvendo a produção de alimentos e a alimentação saudável, podem trazer para os alunos visitantes "fundamentalmente é a vivência da coisa, é ver de perto, ver de perto uma galinha, ver de perto uma casa de farinha" (DF2). Também "é que a comida é saudável, não tem nenhum defensivo agrícola” (DF3).

A maioria dos entrevistados em São Paulo afirmou que existem nos empreendimentos atividades educativas desenvolvidas que visam apresentar a forma de produção e origem dos alimentos e a alimentação saudável. Alguns exemplos passam pelo passeio no cafezal e nas diversas etapas, além da plantação, explicando qual é o melhor tipo, como se separam os grãos, e como a produção é livre de agrotóxicos.

Em outro empreendimento é abordado o ciclo de produção do caqui, produzido de forma natural, sem agrotóxicos e produtos químicos. Em um dos empreendimentos, "as crianças passam pela horta orgânica. As menores plantam sementes e ajudam a regar. Também lhes é mostrado o processo de adubagem e compostagem. As crianças menores são motivadas a plantar mudinhas e árvores frutíferas. Algumas se interessam por consumir os produtos ali mesmo" (SP3).

No entanto, em duas propriedades ainda não existem atividades educativas desenvolvidas que visam apresentar a forma de produção e origem dos alimentos e a alimentação saudável.

\section{CONSIDERAÇÕES FINAIS}

O turismo rural pedagógico caracteriza-se como um conjunto de atividades educativas realizadas no âmbito das propriedades rurais, utilizando como recurso didático as atividades agrícolas, pecuárias e os recursos naturais e culturais com pequenas melhorias nas infraestruturas existentes. Destina-se basicamente ao público estudantil infantojuvenil adequando-se enquanto prática educativa desenvolvida em complemento ao ensino escolar.

A análise dos dados coletados acerca das funções do turismo rural pedagógico evidencia que a prática desse tipo de atividade possui um conjunto de características que permitem ganhos em vários aspectos: econômicos, na medida em que possibilita aos proprietários aumentar a renda da família, agregando valor aos produtos e serviços desenvolvidos nas propriedades; sociais, relacionados à autoestima dos proprietários e o reconhecimento por parte da comunidade do trabalho desenvolvido nas propriedades; educativos, por possibilitar aos grupos escolares experiências concretas, com a exposição de saberes e fazeres associados ao meio rural e natural; ambientais evidenciados pela preocupação dos proprietários em promover a educação ambiental junto aos grupos recebidos; e de segurança alimentar, a partir do contato direto com atividades que favorecem o reconhecimento da origem dos alimentos.

Diante dessas constatações, confirma-se o caráter multifuncional da agricultura e dos espaços rurais a partir da prática do turismo rural pedagógico. Ao mesmo tempo, evidencia-se o papel desempenhado pelas propriedades rurais no contexto da educação, como também promovendo a integração dos habitantes do rural e o urbano em uma perspectiva de desenvolvimento rural. 


\section{REFERÊNCIAS}

BERTACCI, M. La scuola e le fattorie didattiche. In: BERTOLINI, S. (Ed.). Nuovi educatori ambientali / 2 Esperienze seminariali nel Master in Educazione ambientale. Quaderni INFEA 4, Regione Emilia-Romagna, 2005. Disponível em: http://www.ermesambiente.it/wcm/infea/sezioni_laterali/formazione/master_in_ea/ Master_EA/master_ea/infean4.pdf. Acesso em: 12 jun. 2011.

CAFFARELLI, J. et al. Creér une ferme pédagogique: de l'idée à la realization. Dijon: Educagri Editions. 2010.

CARNEIRO, M. J.; MALUF, R. S. Introdução. In: MALUF, R. S.; CARNEIRO, M. J. (Org.). Para além da produção: multifuncionalidade e agricultura familiar. Rio de Janeiro: Mauad Editora, 2003.

GURRIERI, C. Scuola in Fattoria: dal produttore al consumatore verso un consumo consapevole. In: La rete delle Aziende e delle Fattorie Didattiche in Sicilia. La documentazione dell'esperienza. v. 2. Regione Sicilia/Arpa, 2008. Disponível em: www.arpa.sicilia.it/UploadDocs/1369_Fattorie_Didattiche.pdf. Acesso em: 22 jul. 2011.

HINRICHS, C. et al. Growing the links between farms and schools: a how-to guidebook for Pennsylvania farmers. Center for Rural Pensylvania, 2008. Disponível em: http://www.farmtoschool.org/files/publications189.pdf. Acesso em: 22 maio 2011.

JOLLY, L. et al. The Farm as a Pedagogical Resource: background for and evaluation of the co-operation between agriculture and primary school in the county of Nord-Trondelag, Norway, 2004. In: Proceedings of the Sixth European IFSA Symposium: farming and rural systems - research and extension, v. II, p. 497-507. Serviços de Reprografia da Utad, Vila Real, Portugal. Disponível em: www.livinglearning.org/.../ The_Farm_as_a_Pedagogical_Resource_Portugal.pdf. Acesso em: $12 \mathrm{mar} .2011$.

KROGH, E. et al. The Farm as a Pedagogical Resource: an evaluation of the co-operation between agriculture and primary school in the county of Nord-Trondelag, Norway, 2004. 6th European Symposium on Farming and Rural Systems Research and Extension. Vila Real, Portugal. Disponível em: http://www.livinglearning.org/ PDF\%20documents/The_Farm_as_a_Pedagogical_Resource_Portugal.pdf. Acesso em: 14 mar. 2011.

LOSCH, B. Debating the multifuncionality of Agriculture: from trade negotiations to development policies by the south. Journal of Agrarian Change. v. 4, n. 3, p. 336-360. Jul., 2004.

MARSDEN, T.; SONNINO, R. Rural development and the regional state: denying multifunctional agriculture in the UK. Journal of Rural Studies. Great Britain, v. 24, n. 4, p. 422-431. January, 2008.

NAPOLI, L. A new reality for italian rural areas: educational farms. University of Salerno, Italy, 2006. Disponível em: http://www.openstarts.units.it/dspace/bitstream/10077/865/1/f4napoli.pdf. Acesso em: 15 mar. 2011.

NASOLINI, T. Educare all'ambiente e all'alimentazione. In: BERTOLINI, S. (Ed.), Quaderni INFEA (v. 4): Nuovi educatori ambientali / 2 - Esperienze seminariali nel Master in Educazione ambientale. Bologna: Regione Emilia-Romagna, 2005. Disponível em: http://www.ermesambiente.it/wcm/infea/sezioni_laterali/ formazione/master_in_ea/Master_EA/master_ea/infean4.pdf. Acesso em: 20 jun. 2011.

OHE, Y. Educational function of agriculture and farm diversification: evidence from dairy farming experience services in Japan. International Association of Agricultural Economists Conference, Beijing, China, 2009. Disponível em: http://ageconsearch.umn.edu/handle/51557. Acesso em: 12 mar. 2011.

SZNAJDER, M.; PRZEZBÓRSKA, L.; SCRIMGEOUR, F. Agritourism. CABI: UK/USA, 2009.

WANDERLEY, M. N. B. Prefácio. In: MALUF, R. S.; CARNEIRO, M. J. Para além da produção: multifuncionalidade e agricultura familiar. Rio de Janeiro: Mauad Editora, 2003.

\section{Notas}

[1] A expressão "propriedade rural pedagógica" será utilizada neste texto como sinônimo do termo turismo rural pedagógico. Conforme pesquisas, as traduções do termo "propriedade rural pedagógica” variam de acordo com cada país/idioma, porém, apresentam características e finalidades bastante semelhantes.

[2] A definição referida neste parágrafo foi utilizada no contexto da presente pesquisa. 
[3] Projeto desenvolvido entre os anos de 2012 e 2013, com o apoio financeiro do Conselho Nacional de Desenvolvimento Científico e Tecnológico (CNPq) por meio de dois editais: Universal - CNPq No 14/2011 e Chamada MCTI/CNPq/ MEC/Capes No 07/2011. 